\title{
Electrochemistry Study of Permselectivity and Interfacial Electron Transfers of a Branch-Tailed Fluorosurfactant Self-Assembled Monolayer on Gold
}

\author{
Shanshan Li ${ }^{1}$ **D , Qingying Luo ${ }^{1}$, Zhiqing Zhang ${ }^{1}$, Guanghui Shen ${ }^{1}$, Hejun $\mathrm{Wu}^{1}{ }^{1}$, \\ Anjun Chen ${ }^{1}$, Xingyan Liu ${ }^{1}$, Meiliang $\mathrm{Li}^{1}$ and Aidong Zhang ${ }^{2, *}$ \\ 1 College of Food Science, Sichuan Agricultural University, Ya'an 625014, China; \\ cherry12112009@163.com (Q.L.); zqzhang721@163.com (Z.Z.); shenghuishen@163.com (G.S.); \\ hejunwu520@163.com (H.W.); anjunc003@163.com (A.C.); 1xy05@126.com (X.L.); liml@sicau.edu.cn (M.L.) \\ 2 Key Laboratory of Pesticide \& Chemical Biology of Ministry of Education, College of Chemistry, \\ Central China Normal University, Wuhan 430079, China \\ * Correspondence: lss@sicau.edu.cn (S.L.); adzhang@mail.ccnu.edu.cn (A.Z.); Tel.: +86-155-2700-9697 (S.L.)
}

Received: 25 October 2018; Accepted: 15 November 2018; Published: 16 November 2018

\begin{abstract}
We investigated the permselectivity and interfacial electron transfers of an amphiphilic branch-tailed fluorosurfactant self-assembled monolayer (FS-SAM) on a gold electrode by cyclic voltammetry (CV) and electrochemical impedance spectroscopy (EIS). The FS-SAM was prepared by a self-assembly technique and a "click" reaction. The barrier property and interfacial electron transfers of the FS-SAM were also evaluated using various probes with different features. The FS-SAM allowed a higher degree of permeation by small hydrophilic $\left(\mathrm{Cl}^{-}\right.$and $\left.\mathrm{F}^{-}\right)$electrolyte ions than large hydrophobic $\left(\mathrm{ClO}_{4}{ }^{-}\right.$and $\left.\mathrm{PF}_{6}{ }^{-}\right)$ones. Meanwhile, the redox reaction of the $\mathrm{Fe}(\mathrm{CN})_{6}{ }^{3-}$ couple was nearly completely blocked by the FS-SAM, whereas the electron transfer of $\mathrm{Ru}\left(\mathrm{NH}_{3}\right)_{6}{ }^{3+}$ was easier than that of $\mathrm{Fe}(\mathrm{CN})_{6}{ }^{3-}$, which may be due to the underlying tunneling mechanism. For hydrophobic dopamine, the hydrophobic bonding between the FS-SAM exterior fluoroalkyl moieties and the hydrophobic probes, as well as the hydration resistance from the interior hydration shell around the oligo (ethylene glycol) moieties, hindered the transport of hydrophobic probes into the FS-SAM. These results may have profound implications for understanding the permselectivity and electron transfers of amphiphilic surfaces consisting of molecules containing aromatic groups and branch-tailed fluorosurfactants in their structures.
\end{abstract}

Keywords: branch-tailed fluorosurfactant; self-assembled monolayer; amphiphilic surface; permselectivity; electron transfer; "click" reaction

\section{Introduction}

Fluorosurfactants (FSs) are synthetic organofluorine chemical compounds that possess multiple fluorine atoms. Their molecular structure displays a fluorinated hydrophobic "tail" and a hydrophilic "head", wherein the hydrophobic part consists of a fluorocarbon group and the hydrophilic part consists of a polyoxyethylene chain [1]. FSs are well known for their unique physicochemical properties, such as high surface activity, excellent high temperature and chemical resistance, as well as hydrophobic and oleophobic properties, that provides their high suitability for various field applications [2,3]. For example, FSs are widely used to change the hydrophobicity of surfaces in applications concerning antifogging [4], antimicrobial [5], oil-water separation [6], and preparation of electrodes [7] and sensors [8]. Consequently, properties regarding FS-modified surfaces have attracted increasing attention and have been widely investigated in different fields, especially in the electrochemical field [9-11]. 
Great efforts have been devoted to electrochemical studies for in-depth understanding of fundamental structure-property relationships of FS-modified surfaces. For instance, Chen et al. [12,13] investigated applications of FS-modified surfaces in electroanalysis. They found that the electro-oxidation of L-cysteine and tertiary amines becomes more facile at the FS-modified gold electrode. However, most of the reports focused on straight-chain FS-modified surfaces. No direct observations of interfacial phenomena of branch-tailed FS-modified surfaces have been reported. Strengthening the research on branch-tailed FS-modified surfaces and the correlation between molecular structure and surface properties, especially in foundational electrochemical fields, is thus needed.

As an attractive way to functionalize solid surfaces, self-assembled monolayer (SAM) technology offers a unique tool for constructing well-defined, stable structures on surfaces with controlled physicochemical characteristics for a variety of applications [14,15]. Most of the abovementioned investigations are based on the SAM technology. The "click" reaction is one of the most versatile and beneficial chemistry tools in surface modifications [16]. Previous reports showed that this chemoselective and site-specific modification technique can be implemented in the fabrication of SAM-modified electrodes via the triazole-forming "click" reaction between azide-terminated SAM-modified electrodes and alkynyl-terminated molecules [17,18]. In this work, a branch-tailed FS-SAM has been prepared on a gold electrode surface by using the SAM technology and the "click" reaction, as shown in Scheme 1, and was used in a comparative study of various supporting electrolyte ion penetration in the monolayer. Furthermore, the effect of the FS-SAM system on the electrochemical behavior of various probes with different features was also studied.

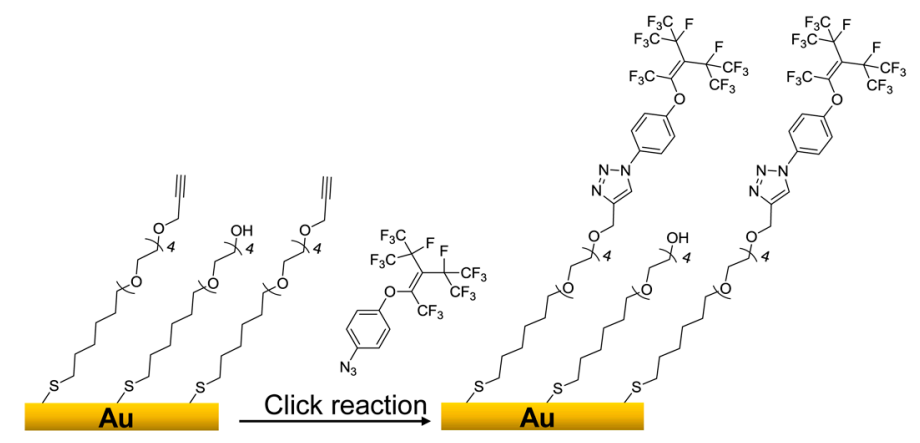

Scheme 1. Schematic illustration of the fabrication of the FS-SAM on gold.

For fabricating the FS-SAM on gold surface, we first mixed $\omega$-tetra (ethylene glycol) hexanethiol $\left(\mathrm{HS}\left(\mathrm{CH}_{2}\right)_{6}\left(\mathrm{OCH}_{2} \mathrm{CH}_{2}\right)_{4} \mathrm{OCH}_{2}-\mathrm{C} \equiv \mathrm{CH}, \mathrm{OEG}-\mathrm{CCH}\right)$ and $\omega$-propargyl tetra (ethylene glycol) hexanethiol $\left(\mathrm{HO}\left(\mathrm{CH}_{2} \mathrm{CH}_{2} \mathrm{O}\right)_{4}\left(\mathrm{CH}_{2}\right)_{6} \mathrm{SH}\right.$, OEG-OH). The obtained mixed thiols were then self-assembled onto the surface of the gold electrode. Subsequently, azide-derivatized $p$-perfluorononenyloxy benzene $\left(\mathrm{N}_{3}-\mathrm{Ar}-\mathrm{O}-\mathrm{C}_{9} \mathrm{~F}_{17}\right)$ was linked to the propargyl-terminated OEG-CCH by forming a stable 1,2,3-triazole ring via a copper(I)-catalyzed "click" reaction. A branch-tailed FS-SAM was then formed on the gold electrode surface. Various techniques, such as X-ray photoelectron spectrometry (XPS), grazing incidence reflectance (GIR) infrared spectroscopy, and contact angle (CA) measurements, were used to characterize the prepared surfaces. Cyclic voltammetry $(\mathrm{CV})$ and electrochemical impedance spectroscopy (EIS) measurements were performed to evaluate the barrier property of the FS-SAM using $\mathrm{Fe}(\mathrm{CN})_{6}{ }^{3-}, \mathrm{Ru}\left(\mathrm{NH}_{3}\right)_{6}{ }^{3+}$, and dopamine as redox probes in the presence of different electrolyte ions. We focus primarily on the effect of film structure on the electrolyte ion penetration and the interfacial electron transfers of structurally different probes. These studies provide a background for future application of FSs in electrochemical systems. 


\section{Results}

\subsection{Characterization of the FS-SAM}

The grafting of $\mathrm{N}_{3}-\mathrm{Ar}-\mathrm{O}-\mathrm{C}_{9} \mathrm{~F}_{17}$ onto the SAMs was characterized by XPS, GIR spectroscopy, and CA measurement. The wide-scan XPS spectrum, as shown in Figure 1A, of the FS-SAM shows characteristic peaks from N 1s (399.9 eV) [19] and F 1s $(687.9 \mathrm{eV})$ [20], which indicates the successful formation of triazole on the SAM. The C 1s core-level spectrum of the FS-SAM can be curve fit into three peak components with BEs of approximately 284.7, 286.4, and 293.1 eV, as shown in Figure 1B, attributable to the $\mathrm{C}-\mathrm{H}, \mathrm{C}-\mathrm{N} / \mathrm{C}-\mathrm{O}[21]$, and $\mathrm{C}-\mathrm{F}$ [20], respectively. The XPS N 1s results in Figure 1C,D supply additional evidence of triazole formation on FS-SAM. For the FS-SAM, only a single peak was observed at $399.8 \mathrm{eV}$, as shown in Figure $1 \mathrm{C}$, whereas the control $\mathrm{N}$ 1s spectrum of $\mathrm{N}_{3}-\mathrm{Ar}-\mathrm{O}-\mathrm{C}_{9} \mathrm{~F}_{17}$ shows two $\mathrm{N}$ 1s peaks at 399.8 and $403.6 \mathrm{eV}$, as shown in Figure 1D, respectively. The splitting of $\mathrm{N} 1 \mathrm{~s}$ peak indicates the presence of two $\mathrm{N}$ species in $\mathrm{N}_{3}-\mathrm{Ar}-\mathrm{O}-\mathrm{C}_{9} \mathrm{~F}_{17}$, which reflects the different charged state of $\mathrm{N}$ atoms in the azide group [22]. The single peak at $399.8 \mathrm{eV}$ for the FS-SAM confirms the reaction between the azide and propargyl groups.
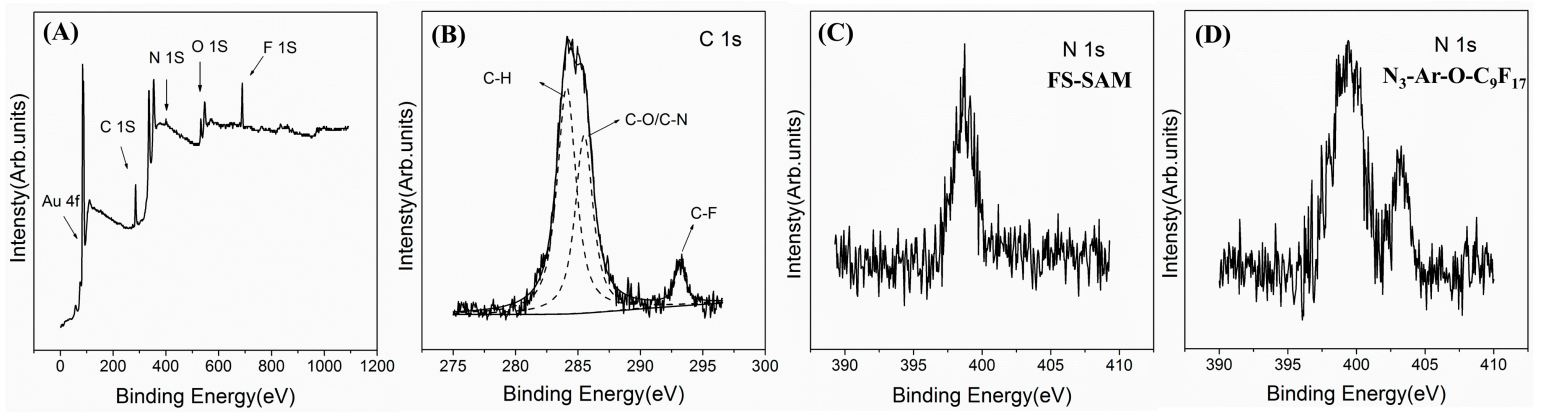

Figure 1. X-ray photoelectron spectrometry (XPS) wide-scan spectrum (A); C 1s core-level spectrum (B); and N 1s core-level spectrum (C) of the fluorosurfactant self-assembled monolayer (FS-SAM); and XPS N 1s core-level spectrum of $\mathrm{N}_{3}-\mathrm{Ar}-\mathrm{O}-\mathrm{C}_{9} \mathrm{~F}_{17}($ D).

In addition, GIR spectra, as shown in Figure 2, also suggest that "click" chemistry was successfully applied to the hydroxyl/propargyl-terminated binary OEG-SAM. The GIR spectrum of $\mathrm{N}_{3}-\mathrm{Ar}-\mathrm{O}-\mathrm{C}_{9} \mathrm{~F}_{17}$ (curve a) clearly reveals the appearance of an absorbance peak at $2107 \mathrm{~cm}^{-1}$, which is characteristic of the azide groups. The peaks at 1284,1183 , and $1135 \mathrm{~cm}^{-1}$ are attributed to C-F stretching vibrations [23] and peaks at 1600 and $1500 \mathrm{~cm}^{-1}$ are the characteristic stretching peaks of the $\mathrm{C}=\mathrm{C}$ bond in the benzene ring [24]. The hydroxyl/propargyl-terminated binary OEG-SAM (curve b) shows characteristic peaks at 3300 and $2130 \mathrm{~cm}^{-1}$ (三C-H and $\mathrm{C} \equiv \mathrm{C}$ stretching) [25], $3500 \mathrm{~cm}^{-1}$ (-OH stretching), and $1103 \mathrm{~cm}^{-1}$ (C-O-C stretching) [24]. After the triazole formation with $\mathrm{N}_{3}-\mathrm{Ar}-\mathrm{O}-\mathrm{C}_{9} \mathrm{~F}_{17}$, the peaks from the propargyl and azide groups disappeared and the characteristic $\mathrm{C}-\mathrm{F}$ and benzene ring stretching peaks were observed on FS-SAM (curve c).

Moreover, CA measurements were used to characterize the surfaces. Initially, the water CA of the hydroxyl/propargyl-terminated SAM was $53 \pm 2^{\circ}$, indicating a moderate wettability of the surface. After the $\mathrm{N}_{3}-\mathrm{Ar}-\mathrm{O}-\mathrm{C}_{9} \mathrm{~F}_{17}$ grafting onto the surface, the CA value increased to $121 \pm 2^{\circ}$ for the formative FS-SAM, resulting from the highly hydrophobic $-\mathrm{CF}_{3}$ groups. All the above evidence demonstrates the successful grafting of $\mathrm{N}_{3}-\mathrm{Ar}-\mathrm{O}-\mathrm{C}_{9} \mathrm{~F}_{17}$ into the hydroxyl/propargyl-terminated SAMs.

We further optimized the condition for preparing the FS-SAM, and characterized the composition of the monolayers by CA [26,27], EIS [28], and XPS measurements. The results revealed that the optimal assembly solution for preparing the binary OEG-SAM is with the OEG-CCH fraction of 25\%. Under the optimization condition, the obtained FS-SAM consists of $56 \%$ FS and $44 \%$ OEG-OH. The details can be seen in Section 1 in the Supplementary material. Since the molecular chain of FS is longer than that of $\mathrm{OEG}-\mathrm{CCH}$, and the tailed $-\mathrm{C}_{9} \mathrm{~F}_{17}$ group has a high occupied surface area, a compact and highly fluorinated surface can be obtained. 


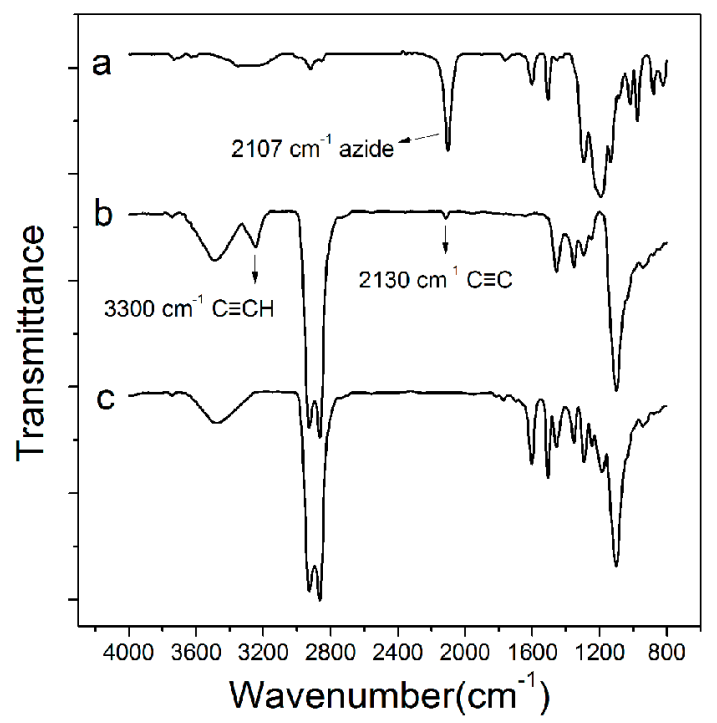

Figure 2. Grazing incidence reflectance (GIR) spectra of the $\mathrm{N}_{3}-\mathrm{Ar}-\mathrm{O}-\mathrm{C}_{9} \mathrm{~F}_{17}$ (curve a), the binary OEG-SAM (curve b), and the FS-SAM (curve c).

\subsection{Electrolyte Ion Permeability of the FS-SAM}

The electrochemical response of a thin film is strongly influenced by electrolyte properties, such as ion charge, size, and hydrophilicity/hydrophobicity. It is well known that SAMs formed on substrates are not perfectly uniform but may have some defects and allow some degree of penetration by solvent molecules and electrolyte ions. To obtain insight into the ion permeability of the FS-SAM, we used CV to study the film capacitance $(C)$ ( $C$ gives rise to current during the charging of the electrode double layer and exhibits a direct correlation with supporting electrolyte) in different inert electrolytes without any redox species. Figure 3 shows the $\mathrm{CV}$ data of the FS-SAM-modified gold electrode between -200 and $200 \mathrm{mV}$ in $0.1 \mathrm{M} \mathrm{KCl}$ (curve a), $0.1 \mathrm{M} \mathrm{KF}$ (curve b), $0.1 \mathrm{M} \mathrm{LiClO}_{4}$ (curve c), and $\mathrm{KPF}_{6}$ (curve d) at $50 \mathrm{mV} / \mathrm{s}$. Table 1 exhibits the calculated film capacitances from the corresponding CV data according to the formula $C=i_{c} / 2 v A$, where $i_{c}$ is the charging current $(\mu \mathrm{A}), v$ is the scan rate $(\mathrm{mV} / \mathrm{s})$, and $A$ is the electrode area $\left(\mathrm{cm}^{2}\right)[29]$.

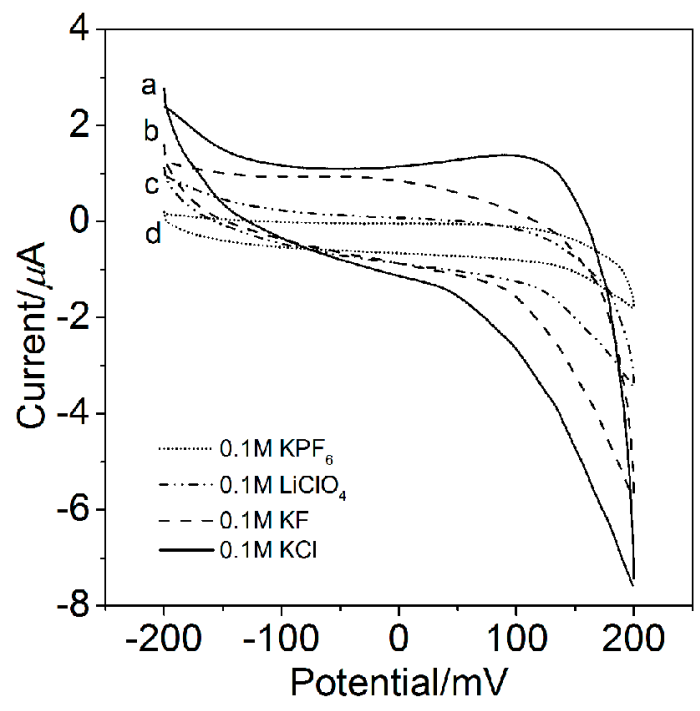

Figure 3. Cyclic voltammetry (CV) on the FS-SAM-modified gold electrode between -200 and $200 \mathrm{mV}$ in different electrolyte solutions: $0.1 \mathrm{M} \mathrm{KCl}$ (curve a), $0.1 \mathrm{M} \mathrm{KF}$ (curve b), $0.1 \mathrm{M} \mathrm{LiClO}_{4}$ (curve c), and $\mathrm{KPF}_{6}$ (curve d). Scan rate, $50 \mathrm{mV} / \mathrm{s} . \mathrm{pH}: 7.0$. 
As shown in Table 1, the capacitance of the FS-SAM is larger in hydrophilic $\mathrm{Cl}^{-}$[30] and F- [31] solution than that in hydrophobic $\mathrm{ClO}_{4}{ }^{-}$[32] and $\mathrm{PF}_{6}{ }^{-}$[30] solution. The largest and the least film capacitance was obtained in the $\mathrm{Cl}^{-}$and $\mathrm{PF}_{6}{ }^{-}$solutions, respectively. The results indicate that the FS-SAM permits the solvent and the hydrophilic ions, but not the hydrophobic ions, to permeate into it. On one hand, this phenomenon might be ascribed to the hydrophobic bond formation between the hydrophobic ions and the $p$-perfluorononenyloxy benzene moieties at the exterior of the FS-SAM. On the other hand, amphiphilic SAMs that consists of OEG and hydrophobic components have been reported to possess a hydration shell around the OEG moieties [33]. Transporting into the hydration interior of the FS-SAM is thermodynamically unfavorable for the hydrophobic $\mathrm{ClO}_{4}^{-}$and $\mathrm{PF}_{6}^{-}$ions. Consequently, the capacitance of the FS-SAM decreased in hydrophobic electrolyte solutions.

Moreover, the ionic sizes of $\mathrm{ClO}_{4}{ }^{-}$and $\mathrm{PF}_{6}{ }^{-}$ions are larger than the sizes of $\mathrm{Cl}^{-}$and $\mathrm{F}^{-}$. The large sizes of the former will certainly defy their chances of permeation. Meanwhile, we observed that the capacitance of the FS-SAM is smaller in KF than that in $\mathrm{KC} 1$ solutions. This finding means that FS-SAM allows $\mathrm{C}^{-}$to permeate into the interior more easily compared with $\mathrm{F}^{-}$, which exhibits good hydrophilicity. This result may also be ascribed to the large size of the hydrated $\mathrm{F}^{-}$, thus hindering its transport in the layer. A similar phenomenon about the film capacitance of the alkanethiol SAMs in $\mathrm{C}^{-}$and $\mathrm{F}^{-}$solutions has been observed by Porter and coworkers [34].

Table 1. Capacitance $(C)$ results of the FS-SAM-modified gold electrodes in different electrolytes.

\begin{tabular}{ccccc}
\hline Electrolyte & $\mathbf{0 . 1} \mathbf{~ M ~ K C l}$ & $\mathbf{0 . 1} \mathbf{M ~ K F}$ & $\mathbf{0 . 1} \mathbf{M ~ \mathbf { L C l O } _ { \mathbf { 4 } }}$ & $\mathbf{0 . 1} \mathbf{M ~ K P F}$ \\
\hline$C\left(\mu \mathrm{F} / \mathrm{cm}^{2}\right)$ & $0.73 \pm 0.03$ & $0.55 \pm 0.04$ & $0.25 \pm 0.01$ & $0.22 \pm 0.06$ \\
\hline
\end{tabular}

\subsection{Electrochemical Response of Hydrophilic Probes on the FS-SAM}

$\mathrm{CV}$ and EIS are powerful tools to investigate the electrochemical properties of SAM-modified electrodes by using redox probes. In this study, two hydrophilic redox probes, namely, $\mathrm{Fe}(\mathrm{CN})_{6}{ }^{3-}$ and $\mathrm{Ru}\left(\mathrm{NH}_{3}\right)_{6}{ }^{3+}[35]$, were used to investigate the blocking property and interfacial electron transfers of the FS-SAM. The control experiments on the binary OEG-SAM-modified gold electrode and bare gold are also performed for comparison.

\subsection{1. $\mathrm{Fe}(\mathrm{CN})_{6}{ }^{3-}$ Redox Reaction}

Figure $4 \mathrm{~A}$ shows the $\mathrm{CV}$ data and Figure 4B shows the EIS data of the SAM-modified gold electrodes in $10 \mathrm{mM} \mathrm{K}_{3} \mathrm{Fe}(\mathrm{CN})_{6}$ with different supporting electrolytes. Each of the EIS spectra consists of a semicircle portion and a linear line portion, referring to the electron transfer reaction and diffusion, respectively. The semicircle diameter represents the charge transfer resistance $\left(R_{c t}\right)$ at the electrode surface. Using the corresponding $R_{c t}$ values from the EIS spectra, the rate constant $\left(k_{0}\right)$ values of $\mathrm{Fe}(\mathrm{CN})_{6}{ }^{3-}$ for the binary OEG-SAM and FS-SAM-modified electrodes were determined (details can be seen in Section 2 in the Supplementary Information). The obtained results of CV and EIS analysis are summarized in Table 2. 

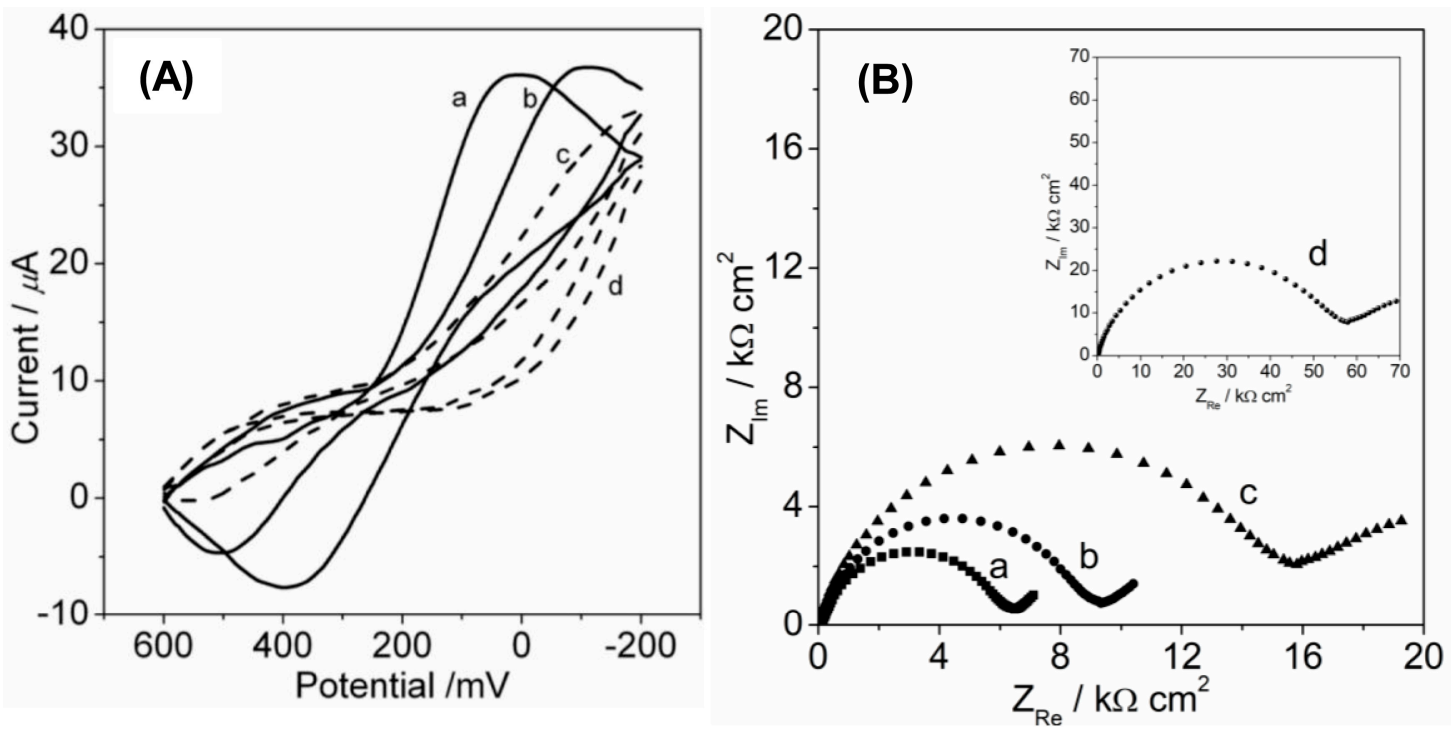

Figure 4. $\mathrm{CV}$ (A) and electrochemical impedance spectroscopy (EIS) (B) of $10 \mathrm{mM} \mathrm{Fe}(\mathrm{CN})_{6}{ }^{3-}$ in different electrolyte solutions on the binary OEG-SAM and the FS-SAM-modified gold electrodes: the binary OEG-SAM-modified gold electrodes in $0.1 \mathrm{M} \mathrm{KCl}$ (curve a) and $0.1 \mathrm{M} \mathrm{KPF}_{6}$ (curve $\mathbf{b}$ ) and the FS-SAM-modified gold electrodes in $0.1 \mathrm{M} \mathrm{KCl}$ (curve c) and $0.1 \mathrm{M} \mathrm{KPF}_{6}$ (curve d). CV scan rate, $100 \mathrm{mV} / \mathrm{s} ; \mathrm{pH}: 7.0$.

Table 2. CV and EIS results for $10 \mathrm{mM} \mathrm{Fe}(\mathrm{CN})_{6}{ }^{3-}$ on different electrodes.

\begin{tabular}{cccccc}
\hline Probe & Electrode & Electrolyte & $\boldsymbol{\Delta} \boldsymbol{E}_{\boldsymbol{p}} / \mathbf{m V}$ & $\boldsymbol{R}_{\boldsymbol{c t}} / \mathbf{\Omega} \mathbf{~ m}^{\mathbf{2}}$ & $\boldsymbol{k}_{\mathbf{0}} / \mathbf{c m}^{-\mathbf{s}^{-\mathbf{1}}}$ \\
\hline \multirow{2}{*}{$\mathrm{Fe}(\mathrm{CN})_{6}{ }^{3-}$} & \multirow{2}{*}{ Binary OEG-SAM } & $0.1 \mathrm{M} \mathrm{KCl}$ & 391 & 6359 & 0.42 \\
& & $0.1 \mathrm{M} \mathrm{KPF}$ & 602 & 9374 & 0.28 \\
\cline { 2 - 6 } & \multirow{2}{*}{ FS-SAM } & $0.1 \mathrm{M} \mathrm{KCl}$ & - & 15681 & 0.17 \\
& $0.1 \mathrm{M} \mathrm{KPF}$ & - & 58139 & 0.05 \\
\hline
\end{tabular}

The peak potential difference $\left(\Delta E_{P}\right)$ and $R_{c t}$ values are used as a measure of electron transfer rate on the SAM-modified electrodes, with larger $\Delta E_{P}$ and $R_{c t}$ indicating a slower electron transfer, and we interpret any increase in this value to be caused by surface imperfections or barriers. On the bare gold electrode (data not shown), $\mathrm{Fe}(\mathrm{CN})_{6}{ }^{3-}$ displays a well-defined response in $0.1 \mathrm{M} \mathrm{KCl}$ solution, with a CV $\Delta E_{p}$ value of $72 \mathrm{mV}$ and an $R_{c t}$ value of $0.96 \Omega \mathrm{cm}^{2}$. Figure $4 \mathrm{~A}, \mathrm{~B}$ and Table 2 show that the $\Delta E_{p}$ and $R_{c t}$ values (curve a) of the binary OEG-SAM-modified electrodes in $0.1 \mathrm{M} \mathrm{KCl}$ solution, as expected, are high owing to the inhibited electron transfer by the OEG-SAM on the electrode surface. Additionally, the increase in $\Delta E_{p}$ and $R_{c t}$ was great when $\mathrm{KPF}_{6}$ (curve b) was used as an electrolyte instead of $\mathrm{KCl}$ (curve a). This result indicates that the electron transfer rate between the electrode and $\mathrm{Fe}(\mathrm{CN})_{6}{ }^{3-}$ is higher for $\mathrm{Cl}^{-}$compared with $\mathrm{PF}_{6}{ }^{-}$, with a $k_{0}$ value of 0.42 and $0.28 \mathrm{~cm} \cdot \mathrm{s}^{-1}$, respectively. The variation in the electron transfer rate with a change in the anion can be explained by the hydrophobicity of the counterion. Given that the chloride ion is less hydrophobic, its migration in and out of the hydrophilic OEG monolayer is more favorable compared with that of $\mathrm{PF}_{6}{ }^{-}$.

After the FS-SAM formation, $\mathrm{CV}$ analysis revealed that the redox reaction of $\mathrm{Fe}(\mathrm{CN})_{6}{ }^{3-}$ is further inhibited by the FS monolayer, as shown in Figure 4A, curves $\mathrm{c}$ and d. Figure 4B shows the comparison of the impedance plots of the binary OEG-SAM and FS-SAM-modified electrodes in $10 \mathrm{mM} \mathrm{K}_{3} \mathrm{Fe}(\mathrm{CN})_{6}$ with $\mathrm{KCl}$ or $\mathrm{KPF}_{6}$ as the supporting electrolyte. The impedance plots of the FS-SAM, as shown in Figure $4 \mathrm{~B}$, curves $\mathrm{c}$ and $\mathrm{d}$, show large semicircles in the high frequency region, suggesting a higher $R_{c t}$ and a stronger blocking ability of the FS-SAM compared with the binary OEG-SAM. Apparently, the electron transfer kinetics of $\mathrm{Fe}(\mathrm{CN})_{6}{ }^{3-}$ decreased in all cases for the FS-SAM systems compared with the binary OEG-SAM systems. Meanwhile, the electron transfer kinetics was lower when $\mathrm{KPF}_{6}$ 
was used as an electrolyte compared with $\mathrm{KCl}, k_{0}$ values are 0.17 and $0.05 \mathrm{~cm} \cdot \mathrm{s}^{-1}$ in the presence of $\mathrm{PF}_{6}{ }^{-}$and $\mathrm{Cl}^{-}$ions, respectively. The results are consistent with our previous hypothesis based on the capacitance of the FS-SAMs. The hydrophobic binding of negatively charged $\mathrm{PF}_{6}{ }^{-}$ions to the hydrophobic $p$-perfluorononenyloxy benzene moieties creates an additional energetic barrier for the transport of negative $\mathrm{Fe}(\mathrm{CN})_{6}{ }^{3-}$ in the monolayer and thus hinders the faradaic reactions.

\subsection{2. $\mathrm{Ru}\left(\mathrm{NH}_{3}\right)_{6}{ }^{3+}$ Redox Reaction}

Figure 5A shows the CV plots and Figure 5B shows the impedance plots of the SAM-modified gold electrodes in $10 \mathrm{mM} \mathrm{Ru}\left(\mathrm{NH}_{3}\right)_{6} \mathrm{Cl}_{3}$ with different supporting electrolytes. Table 3 summarizes the obtained results of CV and EIS analysis. On the bare gold electrode (data not shown), for $\mathrm{Ru}\left(\mathrm{NH}_{3}\right)_{6}{ }^{3+}$ in the presence of $0.1 \mathrm{M} \mathrm{KCl}, \Delta E_{p}(83 \mathrm{mV})$ and $R_{c t}\left(1.24 \Omega \mathrm{cm}^{2}\right)$ values are comparable with those for $\mathrm{Fe}(\mathrm{CN})_{6}{ }^{3-}$ obtained under the same condition, indicating that fast kinetics can be obtained for both the probes on the bare gold electrode.

Unexpectedly, on the binary OEG-SAM-modified electrode, the $\mathrm{CV}$ of $\mathrm{Ru}\left(\mathrm{NH}_{3}\right)_{6}{ }^{3+}$ in the presence of $0.1 \mathrm{M} \mathrm{KCl}$, as shown in Figure $5 \mathrm{~A}$, shows that the $\mathrm{Ru}(\mathrm{III})$ redox reaction is facile. The small $\Delta E_{p}(114 \mathrm{mV})$ implies that the reaction is quasireversible. Such a behavior indicates that the binary OEG-SAM shows a poor blocking ability to the redox reaction of $\mathrm{Ru}\left(\mathrm{NH}_{3}\right)_{6}{ }^{3+}$, which is in contrast to that for $\mathrm{Fe}(\mathrm{CN})_{6}{ }^{3-}$. When $\mathrm{KPF}_{6}$ was used as an electrolyte, both $\Delta E_{p}$ and $R_{c t}$ increased, which are in conformity with our observations using $\mathrm{Fe}(\mathrm{CN})_{6}{ }^{3}$ discussed previously. The hydrophobicity of $\mathrm{PF}_{6}{ }^{-}$ may hinder its migration in and out of the hydrophilic OEG monolayer.
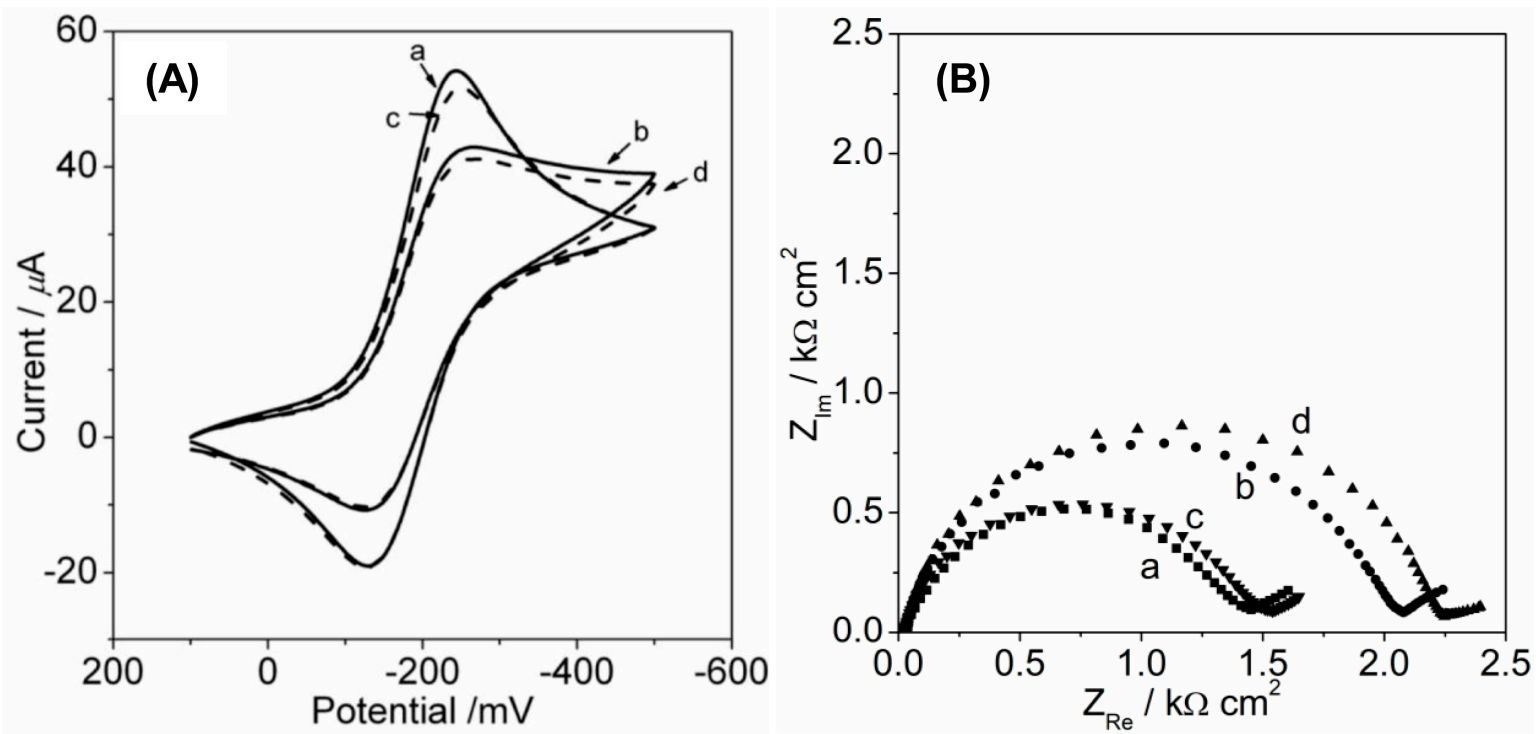

Figure 5. CV (A) and EIS (B) of $10 \mathrm{mM} \mathrm{Ru}\left(\mathrm{NH}_{3}\right)_{6}{ }^{3+}$ in different electrolyte solutions on the binary OEG-SAM and the FS-SAM-modified gold electrodes: the binary OEG-SAM-modified gold electrodes in $0.1 \mathrm{M} \mathrm{KCl}$ (curve a) and $0.1 \mathrm{M} \mathrm{KPF}_{6}$ (curve b), and the FS-SAM-modified gold electrodes in $0.1 \mathrm{M}$ $\mathrm{KCl}$ (curve c) and $0.1 \mathrm{M} \mathrm{KPF}_{6}$ (curve d). $\mathrm{CV}$ scan rate, $100 \mathrm{mV} / \mathrm{s}$. pH: 7.0.

Table 3. $\mathrm{CV}$ and EIS results for $10 \mathrm{mM} \mathrm{Ru}\left(\mathrm{NH}_{3}\right)_{6}{ }^{3+}$ on different electrodes.

\begin{tabular}{|c|c|c|c|c|c|}
\hline Probe & Electrode & Electrolyte & $\Delta E_{p} / \mathrm{mV}$ & $R_{c t} / \Omega \mathrm{cm}^{2}$ & $k_{0} / \mathrm{cm} \cdot \mathrm{s}^{-1}$ \\
\hline \multirow{4}{*}{$\mathrm{Ru}\left(\mathrm{NH}_{3}\right)_{6}{ }^{3+}$} & \multirow{2}{*}{ Binary OEG-SAM } & $0.1 \mathrm{M} \mathrm{KCl}$ & 114 & 1497 & 1.78 \\
\hline & & $0.1 \mathrm{M} \mathrm{KPF}_{6}$ & 131 & 2064 & 1.29 \\
\hline & \multirow{2}{*}{ FS-SAM } & $0.1 \mathrm{M} \mathrm{KCl}$ & 126 & 1524 & 1.75 \\
\hline & & $0.1 \mathrm{M} \mathrm{KPF}_{6}$ & 138 & 2196 & 1.22 \\
\hline
\end{tabular}


The significantly different apparent kinetics of $\mathrm{Ru}\left(\mathrm{NH}_{3}\right)_{6}{ }^{3+}$ and $\mathrm{Fe}(\mathrm{CN})_{6}{ }^{3-}$ on the binary OEG-SAM needs to be clarified. Compared with $\mathrm{Fe}(\mathrm{CN})_{6}{ }^{3-}$, the small $\Delta E_{p}$ and $R_{c t}$ values of $\mathrm{Ru}\left(\mathrm{NH}_{3}\right)_{6}{ }^{3+}$ indicate that the latter displays much faster kinetics than the former. The electrostatic interaction at the monolayer/solution interface may play an important role in the observed response. The binary OEG-SAMs can be assumed to be negatively charged in aqueous solution due to tightly bound hydroxide ions with a hydration shell, similar to the results of OEG- and methyl-terminated SAMs [36,37]. The negative hydration shell may be favorable for the positively charged probe $\mathrm{Ru}\left(\mathrm{NH}_{3}\right)_{6}{ }^{3+}$ to be accessed.

Interestingly, the expected blocking behavior for $\mathrm{Fe}(\mathrm{CN})_{6}{ }^{3-}$ on the FS-SAM was not observed for $\mathrm{Ru}\left(\mathrm{NH}_{3}\right)_{6}{ }^{3+}$. The response of $\mathrm{Ru}\left(\mathrm{NH}_{3}\right)_{6}{ }^{3+}$ on the FS-SAM, in fact, is less suppressed compared with that on the binary OEG-SAM. $\mathrm{Fe}(\mathrm{CN})_{6}{ }^{3-}(6 \AA)$ and $\mathrm{Ru}\left(\mathrm{NH}_{3}\right)_{6}{ }^{3+}(6.4 \AA)$ have comparable sizes, we conclude, if the redox reaction of $\mathrm{Ru}\left(\mathrm{NH}_{3}\right)_{6}{ }^{3+}$ is assumed to occur by access to the electrode surface through the pinhole defects present in the SAMs, the redox reaction of $\mathrm{Fe}(\mathrm{CN})_{6}{ }^{3-}$ should also exhibit facile kinetics. Given that this phenomenon was not observed, the $\mathrm{Ru}\left(\mathrm{NH}_{3}\right)_{6}{ }^{3+}$ redox reaction does not occur by access of the redox species to the electrode surface but by electron tunneling through the bonds, as shown in Scheme 2. The FS molecule with an aliphatic chain length of $2.4 \mathrm{~nm}$ of the $-\mathrm{CH}_{2}-$ and $-\mathrm{CH}_{2} \mathrm{CH}_{2} \mathrm{O}$ - units, provided through bond tunneling pathway [38]; and the delocalized $\pi$ electrons, which are present in the aromatic ring, triazole, and alkene units, can bridge the redox species and the electrode surface effectively to facilitate the electron transfer. The redox reaction of $\mathrm{Ru}\left(\mathrm{NH}_{3}\right)_{6}{ }^{3+}$ has been reported to follow the outer-sphere electron transfer mechanism $[39,40]$. In this case, physical contact between the redox species and the electrode surface is not essential for the electron transfer process since it is favored by the tunneling mechanism. In the case of the FS-SAM in this study, the aromatic and triazole rings with delocalized electrons facilitate the electron transfer of $\mathrm{Ru}\left(\mathrm{NH}_{3}\right)_{6}{ }^{3+}$, and the aliphatic chains provided the bond tunneling pathway. In contrast, the redox reaction of $\mathrm{Fe}(\mathrm{CN})_{6}{ }^{3-}$ follows an inner-sphere electron transfer mechanism, where the access of redox species to the electrode surface is necessary for the electron transfer reaction to occur [40,41].

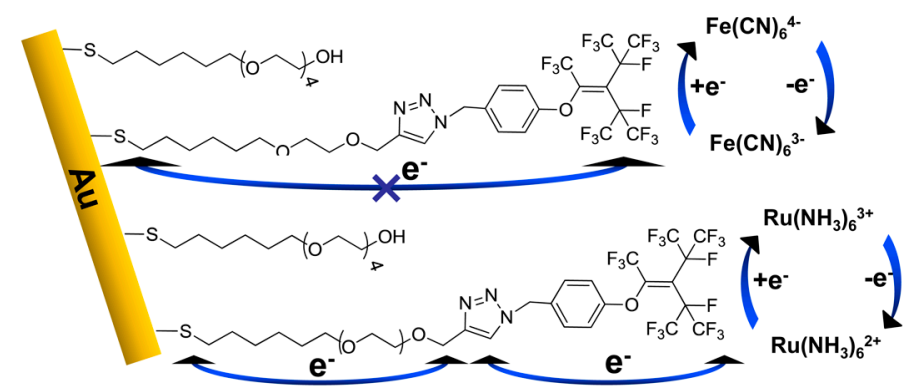

Scheme 2. Proposed electron transfer mechanism for $\mathrm{Fe}(\mathrm{CN})_{6}{ }^{3-}$ and $\mathrm{Ru}\left(\mathrm{NH}_{3}\right)_{6}{ }^{3+}$ on the FS-SAM-modified electrode.

\subsection{Electrochemical Response of Hydrophobic Dopamine ${ }^{+}$on the FS-SAM}

Figure 6 shows CV results for dopamine ${ }^{+}\left(\mathrm{DA}^{+}\right)\left(p \mathrm{~K}_{\mathrm{a}}=8.92\right)$ on the binary OEG-SAM and the FS-SAM-modified electrodes. The results are summarized in Table 4 . With $0.1 \mathrm{M} \mathrm{KCl}$ as a supporting electrolyte, the anodic peak potential $\left(E_{p, a}\right)$ of $\mathrm{DA}^{+}$becomes significantly more positive on the binary OEG-SAM-modified electrode compared with that on the bare gold electrode, as shown in Table 4, and becomes even more positive when we used $\mathrm{KPF}_{6}$ instead of $\mathrm{KCl}$, as shown in Table 3 and Figure 4 . On the FS monolayer, the hydrophobic, singly charged $\mathrm{DA}^{+}$response nearly disappears. 
Table 4. CV results for $10 \mathrm{mM}$ dopamine on different monolayer modified gold electrodes.

\begin{tabular}{ccc}
\hline Electrode & Electrolyte & $\boldsymbol{E}_{\boldsymbol{p}, \boldsymbol{a}} / \mathbf{m V}$ \\
\hline Bare $\mathrm{Au}$ & $0.1 \mathrm{M} \mathrm{KCl}$ & 174 \\
\hline \multirow{2}{*}{ Binary OEG-SAM } & $0.1 \mathrm{M} \mathrm{KCl}$ & 347 \\
& $0.1 \mathrm{KPF}_{6}$ & 539 \\
\hline \multirow{2}{*}{ FS-SAM } & $0.1 \mathrm{M} \mathrm{KCl}$ & - \\
& $0.1 \mathrm{KPF}_{6}$ & - \\
\hline
\end{tabular}

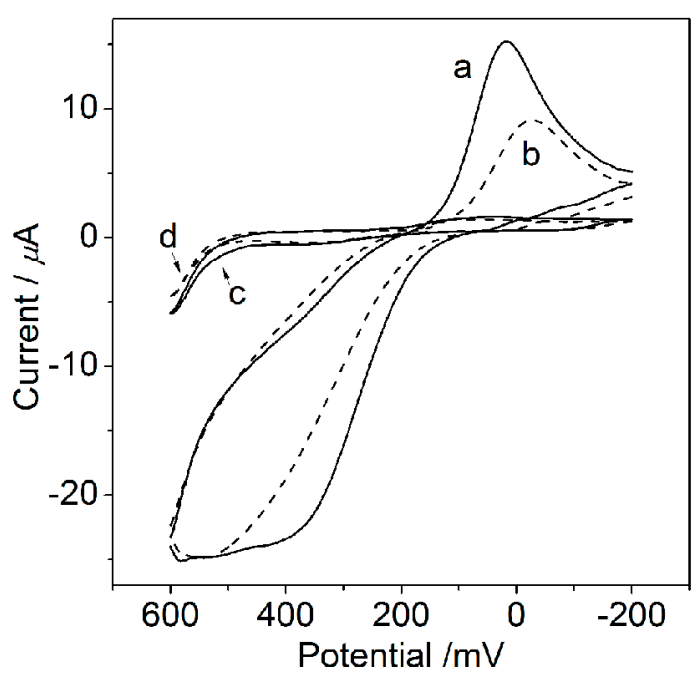

Figure 6. $\mathrm{CV}$ of $10 \mathrm{mM} \mathrm{DA}^{+}$on the binary OEG-SAM-modified gold electrodes in $0.1 \mathrm{M} \mathrm{KCl}$ (curve a) and $0.1 \mathrm{M} \mathrm{KPF}_{6}$ (curve b), and on the FS-SAM-modified gold electrodes in $0.1 \mathrm{M} \mathrm{KCl}$ (curve c) and $0.1 \mathrm{M} \mathrm{KPF}_{6}$ (curve d). pH: 7.0. Scan rate, $100 \mathrm{mV} / \mathrm{s}$. $\mathrm{pH}: 7.0$.

The slow kinetics and poor responses of $\mathrm{DA}^{+}$on the binary OEG-SAM may result from a large distance of access approach to the monolayer surface, which may be due to unfavorable molecular orientation and interactions of $\mathrm{DA}^{+}$with the monolayer, as well as possible complications in the electron transfer mechanism of $\mathrm{DA}^{+}$. The $2 \mathrm{e}^{-}, 2 \mathrm{H}^{+}$redox reaction of $\mathrm{DA}^{+}$shown in Equation (1) may, for example, alter the local $\mathrm{pH}$, affecting surface charge density. Meanwhile, the results reveal that the positive charge of $\mathrm{DA}^{+}$does not significantly facilitate its access to the negative binary OEG-SAM. This phenomenon is different from that of Malem and Mandler's results [42], which reported improved kinetics of $\mathrm{DA}^{+}$on the negative $\mathrm{HS}\left(\mathrm{CH}_{2}\right)_{2} \mathrm{COO}^{-}$SAM compared with that of the bare gold electrode. This outcome may result from the short alkyl chain monolayer used in their study.<smiles>CC(C)CCCCNc1ccc(O)c(O)c1</smiles>

In previous studies, Chen et al. [12,13] studied the oxidation of different electroactive species at a straight-chain FS-modified gold electrode. The results show that the straight-chain FS-SAM showed an inhibiting effect on the oxidation of glucose, uric acid, ascorbic acid, and oxalate, but facilitated L-cysteine oxidation. They think the low coverage of the adsorbed thiol-containing L-cysteine species might account for the more facile electron-transfer kinetics. They also found that the straight-chain FS-SAM facilitated the electron transfers of tertiary amines oxidation, which may be attributable to the FS adsorption layer being more compact. The amines studied include tri- $n$-ethylamine, tri- $n$-propylamine, and tri- $n$-butylamine. Different from Chen's results, in our work, the branch-tailed FS-SAM suppressed the electron transfer of dopamine redox. On one hand, it may partly be due to the structural differences between the branch-tailed FS-SAM and the straight-chain 
ones; on the other hand, it may be caused by the individual differences in the studied species. As we have just investigated the effects of the branch-tailed FS-SAM on only one kind of electroactive organic specie, dopamine, and the obtained data is still very limited. We will conduct further studies on the behavior of more electroactive organic species on the branch-tailed FS-SAMs and compare with the straight-chain ones.

The important feature of surfactant molecules is their amphiphilicity. The specific hydrophobic and hydrophilic portions in the FS-SAM may play a very important role to the response of hydrophobic and hydrophilic probes on the monolayer surface, although other factors may also be important, for example, the electron transfer pathways and electrostatic force. The poor responses of $\mathrm{DA}^{+}$and $\mathrm{Fe}(\mathrm{CN})_{6}{ }^{3-}$ on the FS monolayer demonstrated that the FS-SAM will suppress the response of both hydrophobic and hydrophilic probes. On one hand, for the hydrophobic DA, the hydrophobic bonding at the hydrophobic FS-SAM exterior and the hydration resistance in the interior may hinder the probe to transport into the film. On the other hand, approaching the hydrophobic exterior is thermodynamically unfavorable for the hydrophilic probes, such as $\mathrm{Fe}(\mathrm{CN})_{6}{ }^{3-}$. However, as the FS molecule displays a branch structure of the tail group, the exterior is defective thus allowing some degrees of permeation by solvent and the small size hydrophilic electrolyte ions, similar to $\mathrm{Cl}^{-}$. Therefore, compared with that in hydrophobic electrolyte solution, the FS-SAM is less resistive in hydrophilic electrolyte solution, displays higher film capacitance, and contributes to faster electrochemical kinetics of electroactive species present in the electrolyte solution.

\section{Materials and Methods}

\subsection{Materials}

Perfluorononene $\left(\mathrm{C}_{9} \mathrm{~F}_{18}\right)$ was obtained from Juhua Group Corporation, Quzhou, China. Azide-derivatized $p$-perfluorononenyloxy benzene $\left(\mathrm{N}_{3}-\mathrm{Ar}-\mathrm{O}-\mathrm{C}_{9} \mathrm{~F}_{17}\right)$, $\omega$-tetra (ethylene glycol) hexanethiol $(\mathrm{OEG}-\mathrm{OH})$, and $\omega$-propargyl tetra (ethylene glycol) hexanethiol (OEG-CCH) were synthesized in our laboratory (details can be seen in Section 3 in the Supplementary material). Dopamine, $\mathrm{KCl}, \mathrm{KF}, \mathrm{KPF}_{6}$, $\mathrm{LiClO}_{4}, \mathrm{~K}_{3} \mathrm{Fe}(\mathrm{CN})_{6}, \mathrm{Ru}\left(\mathrm{NH}_{3}\right)_{6} \mathrm{Cl}_{3}, \mathrm{CuBr}$, and tris(benzyltriazolylmethyl)amine were purchased from Sigma-Aldrich. The other reagents were commercially available as the highest purity. Doubly distilled deionized water was used for the preparation of the aqueous solutions.

\subsection{Fabrication of the FS-SAM}

The polycrystalline gold electrode $(2 \mathrm{~mm}$ in diameter, model CHI101, CH Instruments, Inc., Austin, TX, USA) was first polished with chamois leather containing $0.05 \mu \mathrm{m}$ alumina powders for $10 \mathrm{~min}$, rinsed thoroughly with deionized water, and then was electrochemically cleaned in a $0.5 \mathrm{M} \mathrm{H}_{2} \mathrm{SO}_{4}$ solution by cycling from $0 \mathrm{~V}$ to $1.65 \mathrm{~V}$ until a stable current profile was observed. After rinsing with deionized water and ethanol, the electrode was dried in a stream of nitrogen, followed by cleaning with $\mathrm{H}_{2}$ (3 mbar) plasma in a Harrick Plasma Cleaner (Sterilizer PDG-32G, Ithaca, NY, USA) for $10 \mathrm{~min}$. To form thiols SAM, the cleaned gold electrode was incubated in a mixed 3:1 (molar ratio) OEG-OH/OEG-CCH ethanol solution (total thiol concentration: $0.4 \mathrm{mM}$ ) for $24 \mathrm{~h}$, followed by rinsing with ethanol and drying under nitrogen flow. The click reaction was carried out by immersing the propargyl-exposed SAMs in a solution containing $0.1 \mathrm{mM} \mathrm{N}-\mathrm{Ar}-\mathrm{O}-\mathrm{C}_{9} \mathrm{~F}_{17}, 1 \mathrm{mM}$ $\mathrm{CuBr}, 1 \mathrm{mM}$ L-ascorbic acid sodium salt, and $1 \mathrm{mM}$ tris(benzyltriazolylmethyl)amine in 3:1 dimethyl sulfoxide/water for $30 \mathrm{~min}$. Then, the electrode was taken out and rinsed with ethanol and doubly distilled deionized water.

\subsection{Surface Characterization}

XPS measurements were carried out on a VG Multilab 2000 XPS spectrometer (Thermo Electron Corp., Waltham, MA, USA) using monochromated Al $\mathrm{K} \alpha$ radiation. GIR spectra were recorded on a Bruker Optics Tensor 27 Fourier-transform infrared spectrometer (Ettlingen, Germany) coupled to an 
external microscope Hyperion 2000 with grazing angle objective (Ettlingen, Germany). The spectral resolution was set at $4 \mathrm{~cm}^{-1}$ with 1000 co-addition scans. Water CA experiments were measured on a Dataphysics OCA 20 system (Fielderstadt, Germany) at $25^{\circ} \mathrm{C}$.

\subsection{Electrochemical Measurements}

The electrochemical measurements were performed on an Autolab PGSTAT30 system (Eco Chemie BV, Utrecht, The Netherlands). The conventional three-electrode system used consisted of a saturated calomel reference electrode (SCE), a platinum wire auxiliary electrode, and a gold working electrode. Capacitance $(C)$ measurements were conducted by CV scanning in the potential range between 200 and $-200 \mathrm{mV}$ vs. SCE at a scan rate of $50 \mathrm{mV} / \mathrm{s}$. The summed cathodic and anodic charging current $\left(i_{c}\right)$ at $0 \mathrm{mV}$ was then divided twice the scan rate and normalized by the electrode area [29]. The EIS data were recorded in the frequency range from $100 \mathrm{kHz}$ to $0.1 \mathrm{~Hz}$, with a root-mean-square amplitude of $10 \mathrm{mV}$. The Autolab software FRA 4.9.007 was used to fit the impedance data to an appropriate equivalent circuit. From the $R_{c t}$ values obtained from the impedance plots, the rate constant $\left(k_{0}\right)$ of the electron transfer reactions on the monolayer-modified electrodes were calculated according to the protocol described in References [43-45] and the details can be seen in Section 2 in the Supplementary material.

\section{Conclusions}

In this work, we have prepared an amphiphilic branch-tailed FS-SAM on a gold electrode surface via thiol self-assembly followed by a copper (I)-catalyzed "click" reaction modification, and comparatively studied the effect of the FS-SAM system on the electrolyte ion penetration and the electrochemical behavior of redox probes with various hydrophilic/hydrophobic features.

We found that the hydrophilicity/hydrophobicity of the electrolytes exhibit a significant effect on the monolayer capacitance. The FS-SAM displays higher value of the monolayer capacitance in hydrophilic $\mathrm{Cl}^{-}$and $\mathrm{F}^{-}$solutions than that in hydrophobic $\mathrm{ClO}_{4}{ }^{-}$and $\mathrm{PF}_{6}{ }^{-}$solutions, indicating that the FS-SAM allows higher degree of permeation by the small size hydrophilic electrolyte ions than the large size hydrophobic ones. The high degree of permeation by the electrolytes into the monolayer contributes to fast electrochemical kinetics of electroactive species present in the system.

Moreover, the FS-SAM slowed down the response of both hydrophilic and hydrophobic redox probes, even when the probes carry a charge opposite to that of the SAM surface. For hydrophilic electroactive probes, the redox reaction of the $\mathrm{Fe}(\mathrm{CN})_{6}{ }^{3-}$ couple is nearly completely blocked by the FS-SAM. By contrast, the electron transfer of $\mathrm{Ru}\left(\mathrm{NH}_{3}\right)_{6}{ }^{3+}$ is easier than that of $\mathrm{Fe}(\mathrm{CN})_{6}{ }^{3-}$, which may be partly due to the outer-sphere electron transfer mechanism of $\mathrm{Ru}\left(\mathrm{NH}_{3}\right)_{6}{ }^{3+}$. The delocalized electrons in the aromatic ring and triazole can favor the electron transfer of $\mathrm{Ru}\left(\mathrm{NH}_{3}\right)_{6}{ }^{3+}$, and the aliphatic chains can provide a bond tunneling pathway. For hydrophobic $\mathrm{DA}^{+}$, the hydrophobic exterior of the FS-SAM does not help its electrochemical response. The hydrophobic bonding between the exterior fluoroalkyl moieties and the hydrophobic probes, as well as the hydration resistance from the interior hydration shell around the OEG moieties, hinders the hydrophobic probes to transport into the FS-SAM. The results may have profound implications for understanding the permselectivity and electron transfers of amphiphilic surfaces consisting of molecules containing aromatic groups and branch-tailed fluorosurfactants in their structures.

Supplementary Materials: The following are available online, Section 1: Analysis of the composition of the SAMs, Figure S1: Contact angle data and EIS data of the binary OEG-SAMs prepared in the assembly solutions with different OEG-CCH molar fraction, Figure S2: Fractional surface coverage of the SAMs prepared in the assembly solutions with different OEG-CCH molar fraction, Scheme S1: Schematic illustration of the composition of the prepared FS-SAM, Section 2: Detailed computational protocols, Figure S3: Equivalent circuit used for the analysis of EIS data of the electrochemical interface, Section 3: Detailed experimental protocols for the synthesis of compounds, Scheme S2: Synthesis of OEG-OH, Scheme S3: Synthesis of OEG-CCH, Scheme S4: Synthesis of $\mathrm{N}_{3}$-Ar-O-C ${ }_{9} \mathrm{~F}_{17}$, Figure S4: ${ }^{1} \mathrm{H}$ NMR spectra of the $\mathrm{N}_{3}-\mathrm{Ar}-\mathrm{O}-\mathrm{C}_{9} \mathrm{~F}_{17}$. 
Author Contributions: A.Z. conceived and designed the experiments; S.L. and Q.L. performed the experiments; G.S., H.W., M.L. synthetized the compounds; Z.Z., A.C., and X.L. contributed reagents/materials/analysis tools; S.L. wrote the paper.

Funding: This work was supported by the Science and Technology Plan Projects of Sichuan (2018JY0275), the Scientific Research Funded Projects of the Education Department of Sichuan (18ZB0458) and the Young Teachers Funded Projects of Sichuan Agricultural University (03120310).

Conflicts of Interest: The authors declare no conflict of interest.

\section{References}

1. Zaggia, A.; Ameduri, B. Recent advances on synthesis of potentially non-bioaccumulable fluorinated surfactants. Curr. Opin. Colloid Interface Sci. 2012, 17, 188-195. [CrossRef]

2. Buck, R.C.; Murphy, P.M.; Pabon, M. Chemistry, properties, and uses of commercial fluorinated surfactants. In Polyfluorinated Chemicals and Transformation Products; Knepper, T.P., Lange, F.T., Eds.; Springer: Heidelberg, Germany, 2012; Volume 17, pp. 1-24.

3. Wang, L.; Zhang, L.; Lu, C. Applications in analytical chemistry using the attractive properties of non-ionic fluorosurfactants. TRAC-Trend Anal. Chem. 2014, 54, 45-55. [CrossRef]

4. Brown, P.S.; Atkinson, O.D.L.A.; Badyal, J.P.S. Ultrafast oleophobic-hydrophilic switching surfaces for antifogging, self-cleaning, and oil-water separation. ACS Appl. Mater. Int. 2014, 6, 7504-7511. [CrossRef] [PubMed]

5. Thebault, P.; de Givenchy, E.T.; Géribaldi, S.; Levy, R.; Vandenberghe, Y.; Guittard, F. Surface and antimicrobial properties of semi-fluorinated quaternary ammonium thiol surfactants potentially usable for self-assembled monolayers. J. Fluorine Chem. 2010, 131, 592-596. [CrossRef]

6. Brown, P.S.; Bhushan, B. Mechanically durable, superoleophobic coatings prepared by layer-by-layer technique for anti-smudge and oil-water separation. Sci. Rep.-UK 2015, 5, 8701. [CrossRef] [PubMed]

7. Vosgueritchian, M.; Lipomi, D.J.; Bao, Z. Highly conductive and transparent PEDOT: PSS films with a fluorosurfactant for stretchable and flexible transparent electrodes. Adv. Funct. Mater. 2012, 22, 421-428. [CrossRef]

8. Li, Q.; Liu, F.; Lu, C.; Lin, J.M. Aminothiols sensing based on fluorosurfactant-mediated triangular gold nanoparticle-catalyzed luminol chemiluminescence. J. Phys. Chem. C 2011, 115, 10964-10970. [CrossRef]

9. Tang, Y.; Yan, J.; Zhu, F.; Sun, C.; Mao, B. Comparative electrochemical scanning tunneling microscopy study of nonionic fluorosurfactant zonyl FSN self-assembled monolayers on Au (111) and Au (100): A potential-induced structural transition. Langmuir 2011, 27, 943-947. [CrossRef] [PubMed]

10. Yan, J.; Tang, Y.; Sun, C.; Su, Y.; Mao, B. STM study on nonionic fluorosurfactant zonyl FSN self-assembly on $\mathrm{Au}$ (100):(3-111) molecular lattice, corrugations, and adsorbate-enhanced mobility. Langmuir 2010, 26, 3829-3834. [CrossRef] [PubMed]

11. Hu, L.; Xu, G. Applications and trends in electrochemiluminescence. Chem. Soc. Rev. 2010, 39, 3275-3304. [CrossRef] [PubMed]

12. Chen, Z.; Zheng, H.; Lu, C.; Zu, Y. Oxidation of L-cysteine at a fluorosurfactant-modified gold electrode: Lower overpotential and higher selectivity. Langmuir 2007, 23, 10816-10822. [CrossRef] [PubMed]

13. Chen, Z.; Zu, Y. Electrogenerated chemiluminescence of the tris (2, 2'-bipyridine) ruthenium (II)/tertiary amine systems: Effects of electrode surface hydrophobicity on the low-oxidation-potential emission. J. Phys. Chem. C 2009, 113, 21877-21882. [CrossRef]

14. Arvand, M.; Farahpour, M.; Ardaki, M.S. Electrochemical characterization of in situ functionalized gold organosulfur self-assembled monolayer with conducting polymer and carbon nanotubes for determination of rutin. Talanta 2018, 176, 92-101. [CrossRef] [PubMed]

15. Bao, W.J.; Li, J.; Cao, T.Y.; Li, J.; Xia, X.H. Chain-length dependent interfacial immunoreaction kinetics on self-assembled monolayers revealed by surface-enhanced infrared absorption spectroscopy. Talanta 2018, 176, 124-129. [CrossRef] [PubMed]

16. Liang, L.; Astruc, D. The copper (I)-catalyzed alkyne-azide cycloaddition (CuAAC) "click" reaction and its applications. An overview. Coord. Chem. Rev. 2011, 255, 2933-2945. [CrossRef]

17. Wang, T.; Shannon, C. Electrochemical sensors based on molecularly imprinted polymers grafted onto gold electrodes using click chemistry. Anal. Chim. Acta 2011, 708, 37-43. [CrossRef] [PubMed] 
18. Hayat, A.; Sassolas, A.; Marty, J.L.; Radi, A.E. Highly sensitive ochratoxin A impedimetric aptasensor based on the immobilization of azido-aptamer onto electrografted binary film via click chemistry. Talanta 2013, 103, 14-19. [CrossRef] [PubMed]

19. Gehan, H.; Fillaud, L.; Felidj, N.; Aubard, J.; Lang, P.; Chehimi, M.M.; Mangeney, C. A general approach combining diazonium salts and click chemistries for gold surface functionalization by nanoparticle assemblies. Langmuir 2009, 26, 3975-3980. [CrossRef] [PubMed]

20. Ballav, N.; Terfort, A.; Zharnikov, M. Mixing of nonsubstituted and partly fluorinated alkanethiols in a binary self-assembled monolayer. J. Phys. Chem. C 2009, 113, 3697-3706. [CrossRef]

21. Golub, M.A.; Lopata, E.S.; Finney, L.S. X-ray photoelectron spectroscopy study of the effect of hydrocarbon contamination on poly (tetrafluoroethylene) exposed to a nitrogen plasma. Langmuir 1993, 9, 2240-2242. [CrossRef]

22. Gouget-Laemmel, A.C.; Yang, J.; Lodhi, M.A.; Siriwardena, A.; Aureau, D.; Boukherroub, R.; Szunerits, S. Functionalization of azide-terminated silicon surfaces with glycans using click chemistry: XPS and FTIR study. J. Phys. Chem. C 2012, 117, 368-375. [CrossRef]

23. Li, S.; Yang, D.; Tu, H.; Deng, H.; Du, D.; Zhang, A. Protein adsorption and cell adhesion controlled by the surface chemistry of binary perfluoroalkyl/oligo (ethylene glycol) self-assembled monolayers. J. Colloid Interface Sci. 2013, 402, 284-290. [CrossRef] [PubMed]

24. Yang, H.; Yan, R.; Chen, H.; Lee, D.H.; Zheng, C. Characteristics of hemicellulose, cellulose and lignin pyrolysis. Fuel 2007, 86, 1781-1788. [CrossRef]

25. Wang, Y.; Chen, H.; Xiao, Y.; Ng, C.H.; Oh, T.S.; Tan, T.T.Y.; Ng, S.C. Preparation of cyclodextrin chiral stationary phases by organic soluble catalytic 'click' chemistry. Nat. Protoc. 2011, 6, 935. [CrossRef] [PubMed]

26. Cassie, A.B.D. Discussions of the Faraday Society. Faraday Soc. 1948, 3, 11-16. [CrossRef]

27. Israelachvili, J.N.; Gee, M.L. Contact angles on chemically heterogeneous surfaces. Langmuir 1989, 5, $288-289$. [CrossRef]

28. Xing, Y.F.; Li, S.F.Y.; Lau, A.K.H.; O'Shea, S.J. Electrochemical impedance spectroscopy study of mixed thiol monolayers on gold. J. Electroanal. Chem. 2005, 583, 124-132. [CrossRef]

29. Cheng, Q.; Brajter-Toth, A. Permselectivity and high sensitivity at ultrathin monolayers. Effect of film hydrophobicity. Anal. Chem. 1995, 67, 2767-2775. [CrossRef]

30. Huddleston, J.G.; Visser, A.E.; Reichert, W.M.; Willauer, H.D.; Broker, G.A.; Rogers, R.D. Characterization and comparison of hydrophilic and hydrophobic room temperature ionic liquids incorporating the imidazolium cation. Green Chem. 2001, 3, 156-164. [CrossRef]

31. Valente, N.I.; Muteto, P.V.; Farinha, A.S.; Tomé, A.C.; Oliveira, J.A.; Gomes, M.T.S. An acoustic wave sensor for the hydrophilic fluoride. Sens. Actuators B 2011, 157, 594-599. [CrossRef]

32. Xiong, Z.; Zhao, D.; Harper, W.F. Sorption and desorption of perchlorate with various classes of ion exchangers: A comparative study. Ind. Eng. Chem. Res. 2007, 46, 9213-9222. [CrossRef]

33. Shao, Q.; Jiang, S. Molecular understanding and design of zwitterionic materials. Adv. Mater. 2015, 27, 15-26. [CrossRef] [PubMed]

34. Porter, M.D.; Bright, T.B.; Allara, D.L.; Chidsey, C.E.D. Spontaneously organized molecular assemblies. 4. Structural characterization of n-alkyl thiol monolayers on gold by optical ellipsometry, infrared Spectroscopy, and electrochemistry. J. Am. Chem. Soc. 1987, 109, 3559-3568. [CrossRef]

35. Ortiz, B.; Saby, C.; Champagne, G.Y.; Bélanger, D. Electrochemical modification of a carbon electrode using aromatic diazonium salts. 2. Electrochemistry of 4-nitrophenyl modified glassy carbon electrodes in aqueous media. J. Electroanal. Chem. 1998, 455, 75-81. [CrossRef]

36. Dicke, C.; Hähner, G. Interaction between a hydrophobic probe and tri(ethylene glycol)-containing self-assembled monolayers on gold studied with force spectroscopy in aqueous electrolyte solution. J. Phys. Chem. B 2002, 106, 4450-4456. [CrossRef]

37. Dicke, C.; Hähner, G. pH-Dependent force spectroscopy of tri(ethylene glycol)- and methyl-terminated self-assembled monolayers adsorbed on gold. J. Am. Chem. Soc. 2002, 124, 12619-12625. [CrossRef] [PubMed]

38. Petrov, E.G.; May, V. A unified description of superexchange and sequential donor-Acceptor electron transfer mediated by a molecular bridge. J. Phys. Chem. A 2001, 105, 10176-10186. [CrossRef]

39. Kim, J.; Bard, A.J. Electrodeposition of single nanometer-size Pt nanoparticles at a tunneling ultramicroelectrode and determination of fast heterogeneous kinetics for $\mathrm{Ru}\left(\mathrm{NH}^{3}\right)_{6}{ }^{3+}$ reduction. J. Am. Chem. Soc. 2016, 138, 975-979. [CrossRef] [PubMed] 
40. Chen, P.; Fryling, M.A.; McCreery, R.L. Electron transfer kinetics at modified carbon electrode surfaces: The role of specific surface sites. Anal. Chem. 1995, 67, 3115-3122. [CrossRef]

41. Fleischmann, M.; Graves, P.R.; Robinson, J. The raman spectroscopy of the ferricyanide/ferrocyanide system at gold, $\beta$-palladium hydride and platinum electrodes. J. Electroanal. Chem. Interfacial Electrochem. 1985, 182, 87-98. [CrossRef]

42. Malem, F.; Mandler, D. Self-assembled monolayers in electroanalytical chemistry: Application of. omega.-mercapto carboxylic acid monolayers for the electrochemical detection of dopamine in the presence of a high concentration of ascorbic acid. Anal. Chem. 1993, 65, 37-41. [CrossRef]

43. Yang, L.; Wei, W.; Xia, J.; Tao, H.; Yang, P. Electrochemical studies of derivatized thiol self-assembled monolayers on gold electrode in the presence of surfactants. Anal. Sci. 2005, 21, 679-684. [CrossRef] [PubMed]

44. Finklea, H.O.; Snider, D.A.; Fedyk, J.; Sabatani, E.; Gafni, Y.; Rubinstein, I. Characterization of octadecanethiol-coated gold electrodes as microarray electrodes by cyclic voltammetry and ac impedance spectroscopy. Langmuir 1993, 9, 3660-3667. [CrossRef]

45. Ganesh, V.; Pal, S.K.; Kumar, S.; Lakshminarayanan, V. Self-assembled monolayers (SAMs) of alkoxycyanobiphenyl thiols on gold-A study of electron transfer reaction using cyclic voltammetry and electrochemical impedance spectroscopy. J. Colloid Interface Sci. 2006, 296, 195-203. [CrossRef] [PubMed]

Sample Availability: Not available. 